\title{
The tempo-spatial variations of phytoplankton diversities and their correlation with trophic state levels in a large eutrophic Chinese lake
}

Bin Yang a, Yu-Jiao Jiang a *, Wei He a, Wen-Xiu Liu a , Xiang-Zhen Kong a, Sven Erik Jorgensen ${ }^{\text {b }}$

$$
\text { Fu-Liu Xu }{ }^{\text {a** }}
$$

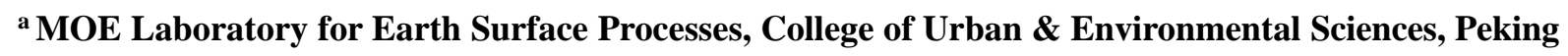
University, Beijing 100871, China

b Section of Toxicology and Environmental Chemistry, Institute A, University of Copenhagen, University Park 2, DK-2100 Copenhagen Ø, Denmarka

*Co-first author

**Correspondence author: Tel./Fax:+86-10-62756122, Email: xufl@urban.pku.edu.cn 


\begin{abstract}
Lake Chaohu is one of the most eutrophic lakes in China. Research on this lake's seasonal and spatial variations in phytoplankton diversity is needed to understand the distribution of eutrophication, as well as to find appropriate comprehensive biodiversity indices to assess the eutrophication status of the lake. The present study indicated that the Margalef index of all samples was as low as $0.799 \pm 0.543$ in summer (August 2011) and as high as $1.467 \pm 0.653$ in winter (February 2012). The Margalef index of the river samples had a high mean value and substantial variation compared with the lake samples. The Peilou index of the lake samples was higher than that of the river samples in summer and autumn (November 2011) but lower than that of the river samples in winter. In spring (May 2012), the Peilou index of the western samples was lower than that of the eastern samples. The spatial distribution of the Shannon-Wiener index was more similar to that of the Peilou index in autumn and winter, while in spring and summer, the spatial distribution was affected by both species richness and evenness. High eutrophication levels occurred in the western lake in spring and summer, whereas high levels occurred in the eastern lake, especially in the middle of the lake, in autumn and winter. The total trophic state index (TSI) in all samples exhibited a significant negative correlation with the Margalef $(r=-0.726)$ and Peilou $(r=-0.530)$ indices but a significant positive correlation with the Shannon-Wiener $(\mathrm{r}=0.654)$ index. The partial correlation analysis results implied that these phytoplankton biodiversity indices could serve as synthetic ecological indicators to assess the eutrophication condition of Lake Chaohu.
\end{abstract}

Keywords: Phytoplankton diversity, Trophic state index, Correlation analysis, Lake Chaohu

\title{
1 Introduction
}

Lake eutrophication is the abnormal structure and function of an aquatic ecosystem and the obvious 
deterioration of the water environment due to the change observed in dissolved oxygen and water transparency when a lake contains excessive nutrients, such as nitrogen and phosphorus (Jin et al., 1990). One major aspect of lake eutrophication is the abnormal proliferation of specific phytoplankton species. Because of phytoplankton's position at the base of aquatic food webs and basic nutritional needs, phytoplankton communities provide unique information about the condition of the ecosystem (McCormick and Cairns, 1994). Phytoplankton responds rapidly and predictably to a wide range of pollutants, thus, the composition and diversity of phytoplankton can provide potentially useful early warning signals of deteriorating conditions, as well as clues to the possible causes. The use of phytoplankton as indicators of ecosystem conditions has historically focused on the effects associated with organic enrichment and other forms of cultural eutrophication (Patrick, 1977). Given the close correlation between phytoplankton and eutrophication, further consideration of the interactive effects of nutrient enrichment on phytoplankton diversity is needed.

The Carlson's trophic state index (TSI) (Carlson, 1977), based on transparency, and the modified Carlson's TSI (Aizaki et al., 1981), based on chlorophyll-a concentration, are most commonly used for lake eutrophication assessment. Later TSIs based on more biological, chemical and physical indicators were calculated (Jin et al., 1990; Primpas et al., 2010; Swanson, 1998; Xu et al., 2001) in an attempt to offer a more suitable and acceptable method for evaluating lake eutrophication. With the exception of chlorophyll-a concentration, ecological indicators, such as phytoplankton cell number, species number, biomass and some form of diversity index, have been involved in both univariate and multivariate approaches in assessing eutrophication conditions in aquatic environments (Danilov and Ekelund, 1999; Washington, 1984; Watson et al., 1997; Xu et al., 2001). Most of the related studies on the relationship between phytoplankton diversity and eutrophication assessment focused on the ability of various diversity 
indices to distinguish between levels of eutrophication (oligotrophic, mesotrophic and eutrophic) and the selection of suitable indicators to identify descriptive classifications for lake trophic states (Danilov and Ekelund, 1999; Karydis and Tsirtsis, 1996; Spatharis and Tsirtsis, 2010). However, the continuous seasonal and spatial distribution of eutrophication levels is equally important in developing a complete picture of the trophic state of a lake. The correlation between typical phytoplankton diversity indices and continuous numerical classes of lake trophic states was analyzed in this paper.

The persistent dominance of Cyanophyta throughout all seasons remained unchanged since the 1980s, which may indicate a new tendency of the response of phytoplankton to eutrophication in Lake Chaohu (Deng et al., 2007; Jiang et al., 2014). Research on seasonal and spatial variations in phytoplankton diversity in Lake Chaohu, a typical eutrophic shallow lake, is necessary for understanding the distribution of eutrophication and finding appropriate synthetic biodiversity indices to assess the level of eutrophication. The objective of the present study was to analyze the feasibility of using phytoplankton diversity as an ecological indicator for assessing lake eutrophication states. It would be beneficial to have an integrated index to appropriately describe and measure the seasonal and spatial variations of eutrophication in Lake Chaohu.

\section{Methods}

\subsection{Sampling sites and analytical methods}

Lake Chaohu, the fifth largest freshwater lake in China, is located in central Anhui Province $\left(30^{\circ} 25^{\prime} 28^{\prime \prime}-31^{\circ} 43^{\prime} 28^{\prime \prime} \mathrm{N}, 117^{\circ} 16^{\prime} 54^{\prime \prime}-117^{\circ} 51^{\prime} 46^{\prime \prime} \mathrm{E}\right)$. This lake has a flat bottom with an area of $770 \mathrm{~km}^{2}$ and an average depth of $3.06 \mathrm{~m}$ (Xu, 1997). Lake Chaohu is a semi-enclosed lake and is artificially controlled by the Chaohu sluice gates. In this study, samples were collected from the surface water of Lake 
Chaohu and the main inflow rivers that drained into the lake (10 samples each) (Fig. 1). Sites L01-L05 were located in western Lake Chaohu (WL), while Sites L06-L10 were located in the eastern part of the lake (EL). Sites R01-R05 were located in the western part of inflow rivers around Lake Chaohu (WR), and Sites R06-R10 were located in the eastern part of rivers around Lake Chaohu (ER). Samples were collected every 3 months from August 2011 to May 2012, representing the water conditions in summer, autumn, winter and spring.

Fig. 1 Twenty sampling sites in and around Lake Chaohu. L01: Nanfeihe River mouth; L02: Tangxihe and Shiwulihe River mouth; L03: Paihe River mouth; L04: the middle of western Lake Chaohu; L05: Sanhe River mouth; L06: east of Mushan Island; L07: Zhaohe River mouth; L08: the middle of eastern Lake Chaohu; L09: Tongyanghe and Jiyuhe River mouth; L10: Shuangqiaohe River mouth; R01: Nanfeihe River; R02: Shiwulihe River; R03: Paihe River; R04: Sanhe River; R05: Baishishanhe River; R06: Zhaohe River; R07: Tongyanghe River; R08: Zhegaohe River; R09: Shuangqiaohe River; R10: Yuxihe River.

A sample of approximately $1 \mathrm{~L}$ of raw water was taken by plexiglass deepwater barrel sampler from each site controlled depth within $0.5 \mathrm{~m}$ to measure the concentrations of total phosphorus (TP), total nitrogen (TN), chemical oxygen demand (COD) and chlorophyll-a (Chl-a). Quantitative samples of the phytoplankton were collected using $10 \mathrm{~L}$ or $20 \mathrm{~L}$ of raw water samples concentrated to approximately 50 $\mathrm{mL}$ through a $25 \#$ plankton net (mesh diameter of $64 \mu \mathrm{m}$ ) in $100 \mathrm{~mL}$ vials, and preserved with $5 \mathrm{~mL}$ $37-40 \%$ formalin for subsequent species identification and counting under an optical digital biological microscope in the laboratory. Phytoplankton biomass (PB) was calculated by multiplying the approximate volume of all algae cells by the approximate density of algae cells (equal to $1 \mathrm{~g} / \mathrm{cm}^{3}$ ). The measurement of 
TP, TN and COD, as well as identification and counting of phytoplankton samples, was described in detail in Jiang et al. (2014). For the Chl-a measurement, a known volume $V l$ of raw water in a given sample was filtered through a $0.8 \mu \mathrm{m}$ cellulose acetate membrane filter. Chl-a pigment was extracted by mixing the sample with a solution of acetone and absolute alcohol (2:1 in volume) after grinding membrane filter with calcium carbonate and quartz sand (Peng and Liu, 1992). After centrifugation, the supernatant was diluted with the mixing solution to $10-\mathrm{mL}$ volume and mixed. Chl-a was measured at two wavelengths using a spectrophotometer and calculated as shown in Eq. (1):

Chla $=\left(12.7 \mathrm{~A}_{663}-2.69 \mathrm{~A}_{645}\right) \times 10 / \mathrm{V} 1$

where Chla is the concentrations of Chl-a $(\mathrm{mg} / \mathrm{L})$ and $A$ is the corrected optical density (with $1 \mathrm{~cm}$ light path) at the respective wavelength.

\subsection{Calculation of phytoplankton diversity indices}

The following equations of four representative phytoplankton diversity indices are the Margalef (1967) richness index, shown in Eq. (2), the Pielou (1966a) evenness index, shown in Eq. (3), the Shannon-Wiener index (Shannon and Weaver, 1963; Pielou, 1966b), shown in Eq. (4) and the Simpson diversity index (Simpson, 1949; Pielou, 1969), shown in Eq. (5):

$\mathrm{D}_{\mathrm{m}}=(\mathrm{S}-1) / \ln N$

$\mathrm{J}=\mathrm{H}^{\prime} / \ln S$

$\mathrm{H}^{*}=-\sum_{i=1}^{S} p_{i} \ln p_{i}$

$\mathrm{D}=1-\sum_{i=1}^{5} p_{i}^{2}$

where $\mathrm{p}_{\tilde{\mathrm{i}}}$ is the relative proportion of species $i$ which is calculated by $\mathrm{n}_{\mathrm{i}} / \mathrm{N}, \mathrm{n}_{\tilde{i}}$ is the number of individuals of species $i$ within a given phytoplankton sample, $N$ is the total number of individuals of all 
species within the given sample, and $S$ is the number of species within the given sample.

In the present study, four phytoplankton diversity indices were calculated based on the raw data for the number of phytoplankton species that was also used in our previous stud for the analysis of the dominant species of phytoplankton and their relationships with environmental factors (Jiang et al., 2014).

\subsection{Calculation of trophic state index (TSI)}

The lake eutrophication levels were determined based on the trophic state index (TSI) for each of the indicators, which is calculated by Eqs. (6) and (7) (Xu et al., 2001):

$\operatorname{TSI}_{i}=\operatorname{TSI}_{k-1}+\left(\left(C_{i}-S_{i, k-1}\right) /\left(S_{i, k}-S_{i, k-1}\right)\right) \times\left(\operatorname{TSI}_{k}-\operatorname{TSI}_{k-1}\right)$

Total TSI $=\Sigma\left(w_{i} \times \operatorname{TSI}_{i}\right)$

where $C_{\tilde{i}}$ is the measured concentration of the $i$-th indicator. $\operatorname{TSI}_{k}$ and $\operatorname{TSI}_{k-1}$ are the $k$-th and $(k-1)$-th scales of the $i$-th indicator, $S_{i, k}$ and $S_{i, k-1}$ are the evaluation standards of $k$-th and $(k-1)$-th scales of the $i$-th indicator (Table S1), and $w_{i}$ is the weight of the $i$-th indicator.

In the present study, total TSI was calculated in equal weights. TP, TN, COD, Chl-a and PB were selected as the assessment indicators. The raw data on TP, TN and COD was previously used as environmental variables for the canonical correspondence analysis (CCA) of phytoplankton community (Jiang et al., 2014). The phytoplankton biomasses (PB) were calculated based on the raw data for phytoplankton cell density that was also used in our previous stud for the analysis of relationships between phytoplankton community and environmental factors (Jiang et al., 2014). The evaluation standards of each indicator as well as the scale of the trophic state index (TSI) for Lake Chaohu followed our previous study (Xu et al., 2001). 


\subsection{Statistical analysis}

In this study, the data processing and graphing were performed using Excel 2007, and the analysis of variance (ANOVA) and correlation analysis were performed using SPSS 18.0 software. All reported levels of significance in seasonal and spatial difference were obtained by a two-way ANOVA model using factors Location (fixed, 4 levels: WL, EL, WR and ER) and Month (fixed, 4 levels: August 2011, November 2011, February 2012 and May 2012), respectively. The post-hoc Tukey's HSD test results were interpreted for multiple comparisons when there was no statistically significant interaction, and the simple main effects were reported when there was a statistically significant interaction term. The descriptive statistics results were represented as the arithmetic mean \pm standard deviation.

\section{Results and Discussion}

\subsection{Seasonal-spatial variations of phytoplankton diversity indices}

There was no significant interaction between the location and month on the Margalef index of Lake Chaohu $(\mathrm{p}=.425)$. The results of the two-way ANOVA showed that the seasonal $(\mathrm{p}=.001)$ and spatial $(\mathrm{p}$ $=.013)$ differences were both significant, but Tukey post-hoc test showed no significant difference among locations $(\mathrm{p}>.05)$. The Margalef index of Lake Chaohu and the rivers around the lake was as low as $0.799 \pm 0.543$ in summer (August 2011), $0.960 \pm 0.565$ in autumn (November 2011), $1.316 \pm 0.545$ in spring (May 2012) and as high as $1.467 \pm 0.653$ in winter (February 2012). The Margalef index of the river samples (WR: $1.279 \pm 0.694$, ER: $1.380 \pm 0.853$ ) had a high mean value and substantial variation compared with the lake samples (WL: $0.931 \pm 0.476$, EL: $0.966 \pm 0.281$ ). This finding indicated that the phytoplankton species richness of the rivers was higher than that of the lake and differed substantially among the rivers. In summer, the Margalef index of the western samples was lower than that of the eastern samples, 
especially the two river samples in the south (R05: 2.623; R06: 1.705). In autumn and winter, the species richness of most of the lake samples was lower than that of the river samples around the lake. In spring, the Margalef index was low in the middle of Lake Chaohu (L06: 0.770; L08: 0.769) as well as in the Shiwulihe River (R02: 0.692). The spatial distribution of species richness varied substantially between spring and summer (Fig. 2).

Fig. 2 The spatial distribution of phytoplankton Margalef index in Lake Chaohu during different seasons. (a) summer (August 2011); (b) autumn (November 2011); (c) winter (February 2012); (d) spring (May 2012). The interpolation map was constructed by ArcGIS software using the Inverse Distance Weighting method.

The spatial distribution of phytoplankton species evenness was very different from that of species richness. There was a statistically significant interaction between the effects of location and month on the Peilou index $(\mathrm{p}=.001)$. The simple main effects analysis showed that the differences among seasons were highly significant in western $(\mathrm{p}<.0005)$ and eastern $(\mathrm{p}=.001)$ Lake Chaohu. In the samples of Lake Chaohu, the Peilou index in winter was significantly lower than in other seasons $(\mathrm{p}<.001)$, as low as $0.242 \pm 0.108$ in western Lake Chaohu and $0.299 \pm 0.070$ in eastern Lake Chaohu (Table 1). There were no seasonal differences in western rivers $(\mathrm{p}=.060)$ and eastern rivers $(\mathrm{p}=.221)$, which had an annual average level of $0.501 \pm 0.200$ and $0.524 \pm 0.180$, respectively. Significant spatial differences in the Peilou index were observed in autumn $(\mathrm{p}=.001)$ and winter $(\mathrm{p}=.004)$, but there were no differences among locations in spring $(\mathrm{p}=.670)$ and summer $(\mathrm{p}=.636)$. In autumn, the Peilou index in western lake samples was as much as $0.693 \pm 0.130$, significantly higher than western $(\mathrm{p}<.0005)$ and eastern $(\mathrm{p}=.008)$ river samples. The Peilou index in western river samples was as low as $0.342 \pm 0.194$, significantly lower than western ( $p$ 
$<.0005)$ and eastern $(\mathrm{p}=.006)$ lake samples, (Table 1). In winter, Peilou index in western river samples was as much as $0.568 \pm 0.244$, significantly higher than western $(\mathrm{p}=.001)$ and eastern $(\mathrm{p}=.006)$ lake samples (Table 1). In summer and autumn, the species evenness of the lake samples was higher than that of most of the river samples around the lake. By contrast, in winter, the species evenness of the lake samples was lower than that of the river samples. In spring, the Peilou index of the sampling location east of Mushan Island (L06: 0.357) and western samples was lower than that of eastern Lake Chaohu (Fig. 3).

Fig. 3 The spatial distribution of phytoplankton Pielou evenness index in Lake Chaohu during different seasons. (a) summer (August 2011); (b) autumn (November 2011); (c) winter (February 2012); (d) spring (May 2012). The interpolation map was constructed by ArcGIS software using the

\section{Inverse Distance Weighting method.}

In autumn and winter, the spatial distribution of the Shannon-Wiener index (Fig. 4) was more similar to that of Peilou index than in other seasons (Fig. 3) because the species evenness could explain more of the variation of phytoplankton species diversity in those seasons. However, in spring and summer, the variation of species diversity was affected by both species richness and evenness. The interaction between location and month on the Shannon-Wiener index was statistically significant $(\mathrm{p}=.003)$, and the seasonal differences were significant in all locations $(\mathrm{p}<.05)$, except in eastern rivers $(\mathrm{p}=.795)$. In the samples of Lake Chaohu, the Shannon-Wiener index in winter was significantly lower than in other seasons $(\mathrm{p}<.05)$, as low as $0.502 \pm 0.217$ in western Lake Chaohu and $0.712 \pm 0.197$ in eastern Lake Chaohu (Table 1). In western river samples, the Shannon-Wiener index in autumn was as low as $0.636 \pm 0.306$, significantly lower than in other seasons $(\mathrm{p}<.05)$ (Table 1). The spatial differences in the Shannon-Wiener index were significant only in autumn $(\mathrm{p}=.018)$ and winter $(\mathrm{p}=.008)$. In autumn, the Shannon-Wiener index in 
western river samples was as low as $0.636 \pm 0.306$, which was significantly lower than in lake samples ( $\mathrm{p}$ $<.05)$ (Table 1). In winter, the Shannon-Wiener index in western lake samples was significantly lower than in river samples $(\mathrm{p}<.05)$ and that in western river samples was significantly higher than in lake samples $(\mathrm{p}$ $<.05)$.

The spatial distribution of the Simpson index (Fig. 5) in all seasons was very similar to that of the Shannon-Wiener index (Fig. 4). The interaction between location and month on the Simpson index was also statistically significant $(\mathrm{p}<.0005)$, and the seasonal differences were significant in all locations $(\mathrm{p}$ $<.05)$ except in eastern rivers $(\mathrm{p}=.551)$. The spatial differences in the Simpson index were significant only in autumn $(\mathrm{p}=.001)$ and winter $(\mathrm{p}=.001)$.

Fig. 4 The spatial distribution of phytoplankton Shannon-Wiener index in Lake Chaohu during different seasons. (a) summer (August 2011); (b) autumn (November 2011); (c) winter (February 2012); (d) spring (May 2012). The interpolation map was constructed by ArcGIS software using the Inverse Distance Weighting method.

Fig. 5 The spatial distribution of phytoplankton Simpson diversity index in Lake Chaohu during different seasons. (a) summer (August 2011); (b) autumn (November 2011); (c) winter (February 2012); (d) spring (May 2012). The interpolation map was constructed by ArcGIS software using the Inverse Distance Weighting method.

Table 1 The seasonal and spatial variation of diversity indices and TSI in Lake Chaohu and its component rivers during the period from August 2011 to May 2012. WL: western Lake Chaohu (L01-L05); EL: eastern Lake Chaohu (L06-L10); WR: western rivers around Lake Chaohu (R01-R05); ER: eastern rivers around Lake Chaohu (R06-R10). 
The Pearson correlation analysis showed that the Simpson index in all samples was significantly positively correlated with the Shannon-Wiener and Peilou indices $(\mathrm{p}<.0005)$ with the correlation coefficients of 0.959 and 0.902 , respectively (Table 2). Considering the high linear correlation between the Simpson and Shannon-Wiener indices, the Simpson index would not be included in subsequent research on the correlation between phytoplankton diversity and eutrophication. The Peilou index in all samples was also significantly positively correlated with Shannon-Wiener index $(r=0.860, p<.0005)$. The Margalef index was significantly positively correlated with the Shannon-Wiener index in all samples $(r=0.366, p$ $<.001)$, especially in river samples $(\mathrm{r}=0.579, \mathrm{p}<.0005)$, but insignificantly correlated with the Peilou index in all samples $(r=0.009, p=0.937)$ (Table 2). The Margalef and Peilou indices described two different aspects of phytoplankton diversity: species richness and evenness. Previous research (Gao et al., 2005) has shown that the Shannon-Wiener index has a strong correlation with the Peilou index.

Table 2 The Pearson correlation coefficients of diversity indices in All samples, Lake samples (L01-L10) and River samples (R01-R10).

\subsection{Variations of TSI and related environmental factors}

An analysis of the seasonal and spatial variations of total TSI (the combination of the TSI for TP, TN, COD, Chl-a and PB) was performed in Fig. 6. There was no significant interaction between the effects of location and month on the total TSI of Lake Chaohu $(\mathrm{p}=.109)$. The seasonal $(\mathrm{p}<.0005)$ and spatial $(\mathrm{p}<.0005)$ differences were both significant. The total TSI in summer was as much as $82.43 \pm 8.55$, significantly higher than in other seasons $(\mathrm{p}<.05)$. The total TSI in lake samples (WL: $80.57 \pm 8.28$, EL: 80.37 \pm 5.70 ) was significantly higher $(\mathrm{p}<.01)$ than in river samples (WR: 73.38 \pm 8.27 , ER: $71.48 \pm 8.61$ ). In summer, the total TSI of western Lake Chaohu and the Shiwulihe River (R02: 96.94) was significantly higher $(\mathrm{p}<.05)$ 
than that of the other river samples. In autumn, the total TSI of the Zhaohe River mouth area (R06: 84.43; L07: 84.78) in the middle of Lake Chaohu was higher than that of western samples. In winter, as in autumn, the eutrophication level of eastern Lake Chaohu, especially east of Mushan Island (L06: 88.45), was higher than that of western samples. In spring, as in summer, the eutrophication level of western lake samples and the Paihe River (R03: 92.65) was significantly higher $(\mathrm{p}<.05)$ than that of eastern samples (Fig. 6). As a whole, in spring and summer, the eutrophication state was more serious in western Lake Chaohu, compared to in autumn and winter, when a high eutrophication state occurred in widespread areas of eastern Lake Chaohu, especially in the middle of the lake.

Fig. 6 The spatial distribution of TSI in Lake Chaohu during different seasons. (a) summer (August 2011); (b) autumn (November 2011); (c) winter (February 2012); (d) spring (May 2012). The interpolation map was constructed by ArcGIS software using the Inverse Distance Weighting method.

There was no significant interaction between the effects of location and month on TP $(p=.652)$, TN (p $=.065), \mathrm{COD}(\mathrm{p}=.387), \mathrm{Chl}-\mathrm{a}(\mathrm{p}=.257)$ and PB $(\mathrm{p}=.543)$. No significant seasonal differences in the concentration of TP $(\mathrm{p}=.881)$ were found. The annual mean concentration was $0.89 \mathrm{mg} / \mathrm{L}$. The ANOVA results showed that the spatial differences were statistically significant $(\mathrm{p}<.0005)$. The concentration of TP $(\mathrm{p}<.005)$ in western rivers around Lake Chaohu was as much as $1.92 \pm 1.97 \mathrm{mg} / \mathrm{L}$, which was much higher than those in other samples of Lake Chaohu. The TN concentration in winter was as much as $24.51 \pm 16.23 \mathrm{mg} / \mathrm{L}$, significantly higher than in other seasons $(\mathrm{p}<.0005)$, especially in western river samples. The COD concentration in summer $(33.18 \pm 15.84 \mathrm{mg} / \mathrm{L})$ was significantly higher than in other seasons $(\mathrm{p}<.05)$, and no significant spatial differences were shown in COD $(\mathrm{p}=.810)$. The Chl-a 
concentration in summer was as much as $39.23 \pm 29.05 \mu \mathrm{g} / \mathrm{L}$, significantly higher than in other seasons (p $<.05)$. No significant differences among seasons $(\mathrm{p}=.054)$ or locations $(\mathrm{p}=.507)$ were observed in PB.

\subsection{The correlation between phytoplankton diversity indices and eutrophication}

To eliminate the effect of other diversity indices, a partial correlation analysis was conducted between the total TSI and each of the phytoplankton diversity indices, with the other diversity indices statistically controlled. The results showed that the total TSI in all samples was significantly negatively correlated with the Margalef index $(r=-.726)$ and the Peilou index $(r=-.530)$, but significantly positively correlated with the Shannon-Wiener index $(\mathrm{r}=.654)$ (Table 3). When a severe state of eutrophication occurred in Lake Chaohu, the number of phytoplankton species reached its lowest point, as did the proportion of non-Cyanophyta species because only some species of dominant cyanobacteria grew rapidly. When the lake eutrophic level was lower, the number of species was higher, as was the proportion of non-Cyanophyta (Jiang et al., 2014). Previous studies have explained why biodiversity decreases when eutrophication increases (Jørgensen, 1988). This finding indicated that the lake eutrophic level is negatively correlated with species richness and evenness. Without the effect of the Margalef and Peilou indices, the positive correlation between total TSI and Shannon-Wiener index could be attributed to the dominance of Microcystis and Anabaena species in Lake Chaohu. Although the Shannon-Wiener index is most strongly affected by the importance values of species in the middle of the sequence, rather than the importance values of the first one, two, or three species (Whittaker, 1972), the so-called middle of the sequence consists primarily of sub-dominant cyanobacteria, especially Microcystis and Anabaena species, in the case of Lake Chaohu. Thus, the Shannon-Wiener index is primarily a measure of sub-dominance as a degree of concentration of importance values of species in the middle of the sequence because their 
importance values also have a positive response to the eutrophication state. The results of the partial correlation analysis implied that these phytoplankton biodiversity indices could serve as synthetic ecological indicators to assess the eutrophication condition of Lake Chaohu.

Additionally, a partial correlation analysis in different sample segments based on different classification methods was conducted. The correlation between phytoplankton diversity indices and total TSI in river samples was stronger than that in lake samples. The correlation coefficients in western and eastern samples were almost the same as that in all samples. The strongest correlation was found in autumn (November 2011) samples. The total TSI in autumn samples was significantly negatively correlated with the Margalef index $(r=-.906)$ and the Peilou index $(r=-.881)$, but significantly positively correlated with the Shannon-Wiener index $(\mathrm{r}=.896)$ (Table 3$)$. The correlation between the Margalef index and TSI was weaker in spring (May 2012) samples. The correlation between the Peilou and Shannon-Wiener indices and TSI was weaker in summer (August 2011) and winter (February 2012) samples.

Table 3 The correlation coefficients found by partial correlation analysis of phytoplankton diversity indices and TSI in All samples, Lake samples (L01-L10), River samples (R01-R10), Western samples (L01-L05 \& R01-R05), Eastern samples (L06-L10 \& R06-R10) and samples in different seasons.

Generally, the phytoplankton diversity in freshwater lakes is affected by both bottom-up effect (nutrient level control) and top-down effect (zooplankton predation control) (Hansson et al., 1998; Jeppesen et al., 1997). With the increasing of nutrient levels, the top-down effect on lake plankton across trophic levels was weakened (Özkan et al., 2014). In eutrophic shallow lakes, the weakening of top-down effect with increasing nutrient levels may be mediated through two factors. First, the weakening of top-down effect with increasing nutrient levels may result from uncoupling of trophic interactions between zooplankton and phytoplankton due to strong top-down predation pressure on zooplankton by fish in eutrophic lakes. 
Previous studies showed that the increasing predation control by fish and the reduced grazing pressure on phytoplankton were corresponding to the increasing nutrient levels (Jeppesen et al., 2000, 2003). Second, eutrophication may also result in dominance of a few strongly competitive and toxic cyanobacteria, which are less palatable or even inedible for most zooplankton (Christoffersen et al., 2002). Therefore, the weakening of top-down effect with increasing nutrient levels may also be indicative of uncoupling of trophic interactions between zooplankton and phytoplankton due to a compositional change in the phytoplankton community toward cyanobacteria-dominant and nutrient-dependent forms. A recent study found that the phytoplankton diversity did decrease with increasing nutrient levels in a eutrophic-hypertrophic lake in Argentina (Fernandez et al., 2012), which could be corroboration or evidence for this hypothesis. However, in other types of lakes such as oligotrophic or mesotrophic lakes, compositions of fish and algae are different from eutrophic lakes (Salcher et al., 2013), thus, confounding of two effects would reduce correlation between nutrients concentration and phytoplankton diversity (Özkan et al., 2014). From the above discussion, we inferred that the correlation relationships between phytoplankton diversity and TSI in eutrophic lakes such as Lake Chaohu might not be suitable for oligotrophic or mesotrophic lakes.

\subsection{Phytoplankton diversity indices as part of an integrated index for eutrophication}

\section{assessment}

The results of most studies on the relation between phytoplankton diversity and eutrophication assessment have shown that most of the commonly used diversity indices cannot distinguish between different levels of eutrophication (oligotrophic, mesotrophic and eutrophic) (Danilov and Ekelund, 1999; Karydis and Tsirtsis, 1996; Spatharis and Tsirtsis, 2010). The result of using only a univariate diversity index to identify 
descriptive classifications for lake trophic states is not ideal because the assessment of eutrophication is a complex process combining independent and dependent variables. The discriminating power of eutrophication assessment schemes is often affected by the interaction between cause (nutrient concentrations) and response (phytoplankton biomass and diversity) variables (Primpas et al., 2010). Neither univariate approaches, nor directly derived indices can adequately describe the trophic status of a body of water. An integrated index of nutrients and phytoplankton communities, based on a multidimensional statistical approach is recommended to assess lake eutrophication.

Compared to single factors such as general species number, cell number, biomass and chlorophyll-a concentration of phytoplankton, diversity indices are more integrated ecological assessment tools with more complete information. Phytoplankton diversity indices are often viewed as directly reflecting the variation in phytoplankton community structure, thus they can more closely mirror the response of an entire aquatic ecosystem to a change in lake trophic state. In future research, it would be beneficial to bring typical phytoplankton diversity indices involving species richness and evenness into schemes of eutrophication assessment. An ideal integrated index could be derived from a combination of weighted principal components accounting for the interaction of phytoplankton diversity and nutrient concentrations through multivariate statistical approaches. A continuous and numerical indicator system could be constructed to appropriately describe and measure the continuous variations of eutrophication with higher resolution of dynamic changes.

\section{Conclusions}

The feasibility of phytoplankton diversity to serve as biological indicator for assessing eutrophication states in Lake Chaohu were investigated in the present study, based on the correlation analysis between 
TSI and phytoplankton diversity indices including Shannon-Wiener index, Margalef index, Simpson index and Peilou index. The partial correlation analysis showed that the TSI exhibited a significant negative correlation with the Margalef $(r=-0.0726)$ and Peilou $(r=-0.530)$ indices but a significant positive correlation with the Shannon-Wiener $(\mathrm{r}=0.654)$ index. The obvious correlations in the seasonal and spatial distributions were also found between TSI and phytoplankton diversity indices. Seasonally, in summer (August 2011), the highest average TSI value was corresponded to the highest average Shannon-Wiener index and the lowest average Margalef index; while, in winter (February 2012), the lowest average TSI value was corresponding to the lowest Shannon-Wiener index and the highest average Margalef index. Spatially, in the western lake, the higher average TSI value was corresponding to the higher average Shannon-Wiener index and the lower average Margalef index; while, in the eastern lake, the lower average TSI value was corresponding to the lower average Shannon-Wiener index and the higher average Margalef index. The seasonal and spatial variations of phytoplankton diversity indexes in Lake Chaohu were attributed to the changes in the number of total phytoplankton species presented in our previous study illustrating greatest in winter (53) and lowest in summer (38), as well as greater in the eastern lake (40) and lower in the western lake (32) (Jiang et al., 2014). These results would result in the conclusion that phytoplankton diversity could serve as biological indicators to combine with TSI to give overall descriptions of the eutrophication states in Lake Chaohu.

\section{Acknowledgments}

The funding for this study was provided by National Project for Water Pollution Control (2012ZX07103-002), the National Science Foundation of China (NSFC) (41271462, 41030529). This work is also supported by a grant from the 111 Project (B14001). 


\section{References}

Aizaki, M., Iwakuma, T., Takamura, N., 1981. Application of modified Carlson's trophic state index to Japanese lakes and its relationship to other parameters related to trophic state. Res. Rep. Natl. Inst. Environ. Stud. 23, 13-31.

Carlson, R.E., 1977. A trophic state index for lakes. Limnol. Oceanogr. 22, 361-369.

Christoffersen, K., Lyck, S., Winding, A., 2002. Microbial activity and bacterial community structure during degradation of microcystins. Aquatic Microbial Ecology 27(2): 125-136.

Danilov, R., Ekelund, N.G.A., 1999. The efficiency of seven diversity and one similarity indices based on phytoplankton data for assessing the level of eutrophication in lakes in central Sweden. Sci. Total Environ. 234 (1-3), 15-23

Deng, D.G., Xie, P., Zhou, Q., Yang, H., Guo, L.G., 2007. Studies on Temporal and Spatial Variations of Phytoplankton in Lake Chaohu. Journal of Integrative Plant Biology 49: 409-418.

Fernandez, C., Parodi, E.R., Caceres, E.J., 2012. Phytoplankton structure and diversity in the eutrophic-hypereutrophic reservoir Paso de las Piedras, Argentina. Limnology 13(1): 13-25.

Gao, X.L., Song, J.M., 2005. Phytoplankton distributions and their relationship with the environment in the Changjiang Estuary, China. Marine Pollution Bulletin 50, 327-335.

Hansson, L.A., Annadotter, H., Bergman, E., Hamrin, S.F., Jeppesen, E., Kairesalo, T., Luokkanen, E., Nilsson, P.A., Sondergaard, M., Strand, J., 1998. Biomanipulation as an application of food-chain theory: Constraints, synthesis, and recommendations for temperate lakes. Ecosystems 1(6): 558-574.

Jeppesen, E., Jensen, J.P., Sondergaard, M., Lauridsen, T., Pedersen, L.J., Jensen, L., 1997. Top-down control in freshwater lakes: The role of nutrient state, submerged macrophytes and water depth. 
Hydrobiologia 342: 151-164.

Jeppesen, E., Jensen, J.P., Sondergaard, M., Lauridsen, T., Landkildehus, F., 2000. Trophic structure, species richness and biodiversity in Danish lakes: changes along a phosphorus gradient. Freshwater Biology 45(2): 201-218.

Jeppesen, E., Jensen, J.P., Jensen, C., Faafeng, B., Hessen, D.O., Sondergaard, M., Lauridsen, T., Brettum, P., Christoffersen, K., 2003. The impact of nutrient state and lake depth on top-down control in the pelagic zone of lakes: A study of 466 lakes from the temperate zone to the arctic. Ecosystems 6(4): 313-325.

Jiang, Y.J., He, W., Liu, W.X., Qin, N., Ouyang, H.L., Wang, Q.M., Kong, X.Z., He, Q.S., Yang, C., Yang, B., Xu, F.L., 2014. The seasonal and spatial variations of phytoplankton community and their correlation with environmental factors in a large eutrophic Chinese lake (Lake Chaohu). Ecological Indicators 40, $58-67$.

Jin, X.C., Liu, H.L., Tu, Q.Y., 1990. Eutrophication of Lakes in China. China Environmental Sciences Press, Beijing (in Chinese).

Jørgensen, S.E., 1988. Use of models as experimental tool to show that structural changes are accompanied by increased exergy. Ecol. Model. 41, 117-126.

Karydis, M., Tsirtsis, G., 1996. Ecological indices: a biometric approach for assessing eutrophication levels in the marine environment. Sci. Total. Environ. 186, 209-219.

Margalef, R., 1967. Some concepts relative to the organization of plankton. Oceanogr. Mar. Biol. Ann. Rev. $5,257-289$.

McCormick, P., Cairns, J.J., 1994. Algae as indicators of environmental change. J. Appl. Phycol. 6, 509-526.

Özkan, K., Jeppesen, E., Davidson, T.A., Sondergaard, M., Lauridsen, T.L., Bjerring, R., Johansson, L.S., 
Svenning, J.C., 2014. Cross-taxon congruence in lake plankton largely independent of environmental gradients. Ecology 95(10): 2778-2788.

Patrick, R., 1977. Ecology of freshwater diatoms. In Werner, D., (ed), The Biology of Diatoms. University of California Press, Berkeley, pp284-332.

Peng, Y.S., Liu, E., 1992. Studies of method on extract chlorophyll a and b. Journal of China Agricultural University 18 (3), 247-250 (in Chinese).

Pielou, E.C., 1966a. The measurement of diversity in different types of biological collections. J. Theoret. Biol. 13, 131-144.

Pielou, E.C., 1966b. Shannon's formula as a measure of specific diversity: its use and misuse. Am. Nat. $100,463-465$.

Pielou, E.C., 1969. An introduction to mathematical ecology. Wiley-Interscience, New York, 286 pp.

Primpas, I., Tsirtsis, G., Karydis, M., Kokkoris, G.D., 2010. Principal component analysis: Development of a multivariate index for assessing eutrophication according to the European water framework directive. Ecological Indicators 10, 178-183.

Salcher, M.M., Posch, T., Pernthaler, J., 2013. In situ substrate preferences of abundant bacterioplankton populations in a prealpine freshwater lake. Isme Journal 7(5): 896-907.

Shannon, C.E., Weaver, W., 1963. The mathematical theory of communication. University of Illinois Press, Urbana, Illinois, 117 pp.

Simpson, E.H., 1949. Measurement of species diversity. Nature 163, 688.

Spatharis, S., Tsirtsis, G., 2010. Ecological quality scales based on phytoplankton for the implementation of Water Framework Directive in the Eastern Mediterranean. Ecological Indicators 10, 840-847.

Swanson, E.R., 1998. Trophic state index revisited. Lake Line 18 (4), 18-20. 
Washington, H.G., 1984. Diversity, biotic and similarity indices. Water Res. 18 (6), 653-694.

Watson, S., McCauley, E., Downing, J., 1997. Patterns in phytoplankton taxonomic composition across temperate lakes of different nutrient status. Limnol. Oceanogr. 42, 487-495.

Whittaker, R.H., 1972. Evolution and measurement of species diversity. Taxon 21, 213-251.

Xu, F.L., 1997. Exergy and structural exergy as ecological indicators for the development state of Lake Chao ecosystems. Ecological Modelling 99 (1), 41-49.

Xu, F.L., Tao, S., Dawson, R.W., Li, B.G., 2001. A GIS-based method of lake eutrophication assessment. Ecological Modelling 144, 231-244. 


\section{Figure captions}

Fig. 1 Twenty sampling sites in and around Lake Chaohu. L01: Nanfeihe River mouth; L02: Tangxihe and Shiwulihe River mouth; L03: Paihe River mouth; L04: the middle of western Lake Chaohu; L05: Sanhe River mouth; L06: east of Mushan Island; L07: Zhaohe River mouth; L08: the middle of eastern Lake Chaohu; L09: Tongyanghe and Jiyuhe River mouth; L10: Shuangqiaohe River mouth; R01: Nanfeihe River; R02: Shiwulihe River; R03: Paihe River; R04: Sanhe River; R05: Baishishanhe River; R06: Zhaohe River; R07: Tongyanghe River; R08: Zhegaohe River; R09: Shuangqiaohe River; R10: Yuxihe River.

Fig. 2 The spatial distribution of phytoplankton Margalef index in Lake Chaohu during different seasons. (a) summer (August 2011); (b) autumn (November 2011); (c) winter (February 2012); (d) spring (May 2012). The interpolation map was constructed by ArcGIS software using the Inverse Distance Weighting method.

Fig. 3 The spatial distribution of phytoplankton Pielou evenness index in Lake Chaohu during different seasons. (a) summer; (b) autumn; (c) winter; (d) spring. The interpolation map was constructed by ArcGIS software using the Inverse Distance Weighting method.

Fig. 4 The spatial distribution of phytoplankton Shannon-Wiener index in Lake Chaohu during different seasons. (a) summer; (b) autumn; (c) winter; (d) spring. The interpolation map was constructed by ArcGIS software using the Inverse Distance Weighting method.

Fig. 5 The spatial distribution of phytoplankton Simpson diversity index in Lake Chaohu during different seasons. (a) summer (August 2011); (b) autumn (November 2011); (c) winter (February 2012); (d) spring (May 2012). The interpolation map was constructed by ArcGIS software using the Inverse Distance Weighting method.

Fig. 6 The spatial distribution of TSI in Lake Chaohu during different seasons. (a) summer (August 2011); (b) autumn (November 2011); (c) winter (February 2012); (d) spring (May 2012). The interpolation map was constructed by ArcGIS software using the Inverse Distance Weighting method. 


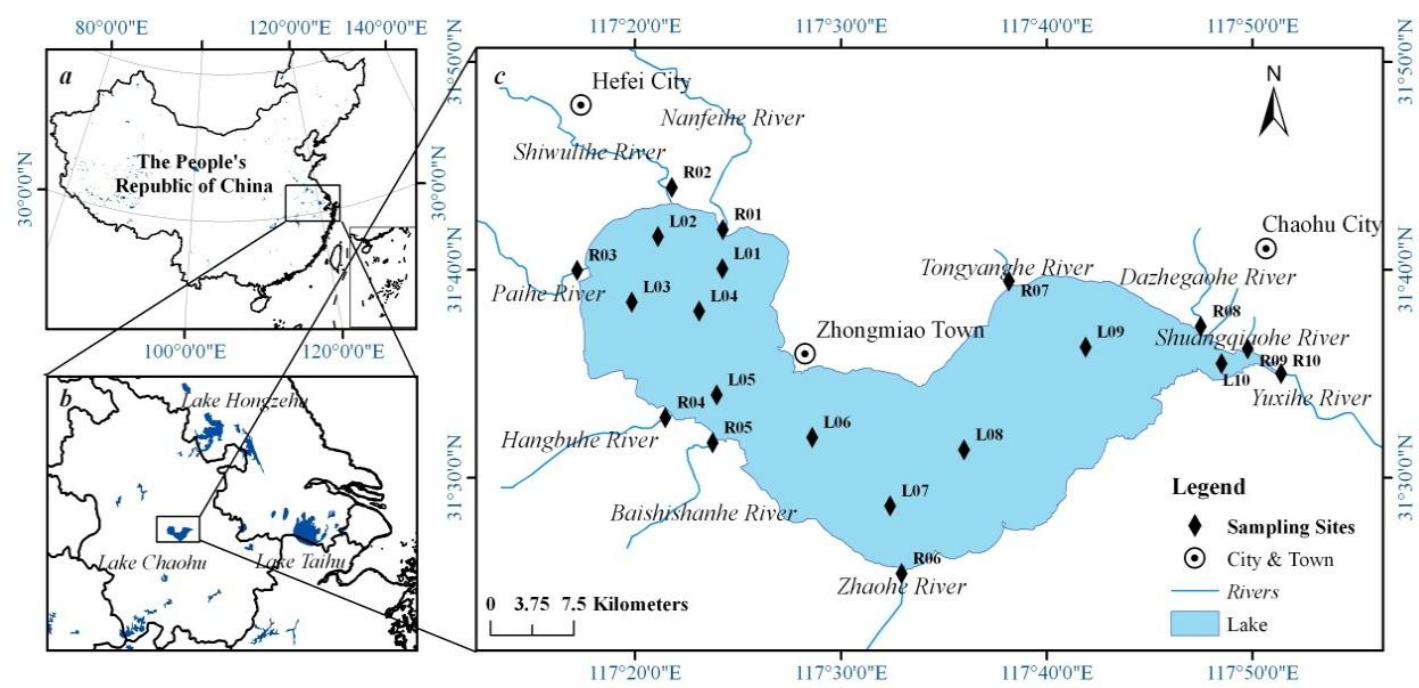

Fig. 1 Twenty sampling sites in and around Lake Chaohu. L01: Nanfeihe River mouth; L02: Tangxihe and Shiwulihe River mouth; L03: Paihe River mouth; L04: the middle of western Lake Chaohu; L05: Sanhe River mouth; L06: east of Mushan Island; L07: Zhaohe River mouth; L08: the middle of eastern Lake Chaohu; L09: Tongyanghe and Jiyuhe River mouth; L10: Shuangqiaohe River mouth; R01: Nanfeihe River; R02: Shiwulihe River; R03: Paihe River; R04: Sanhe River; R05: Baishishanhe River; R06: Zhaohe River; R07: Tongyanghe River; R08: Zhegaohe River; R09: Shuangqiaohe River; R10: Yuxihe River. 


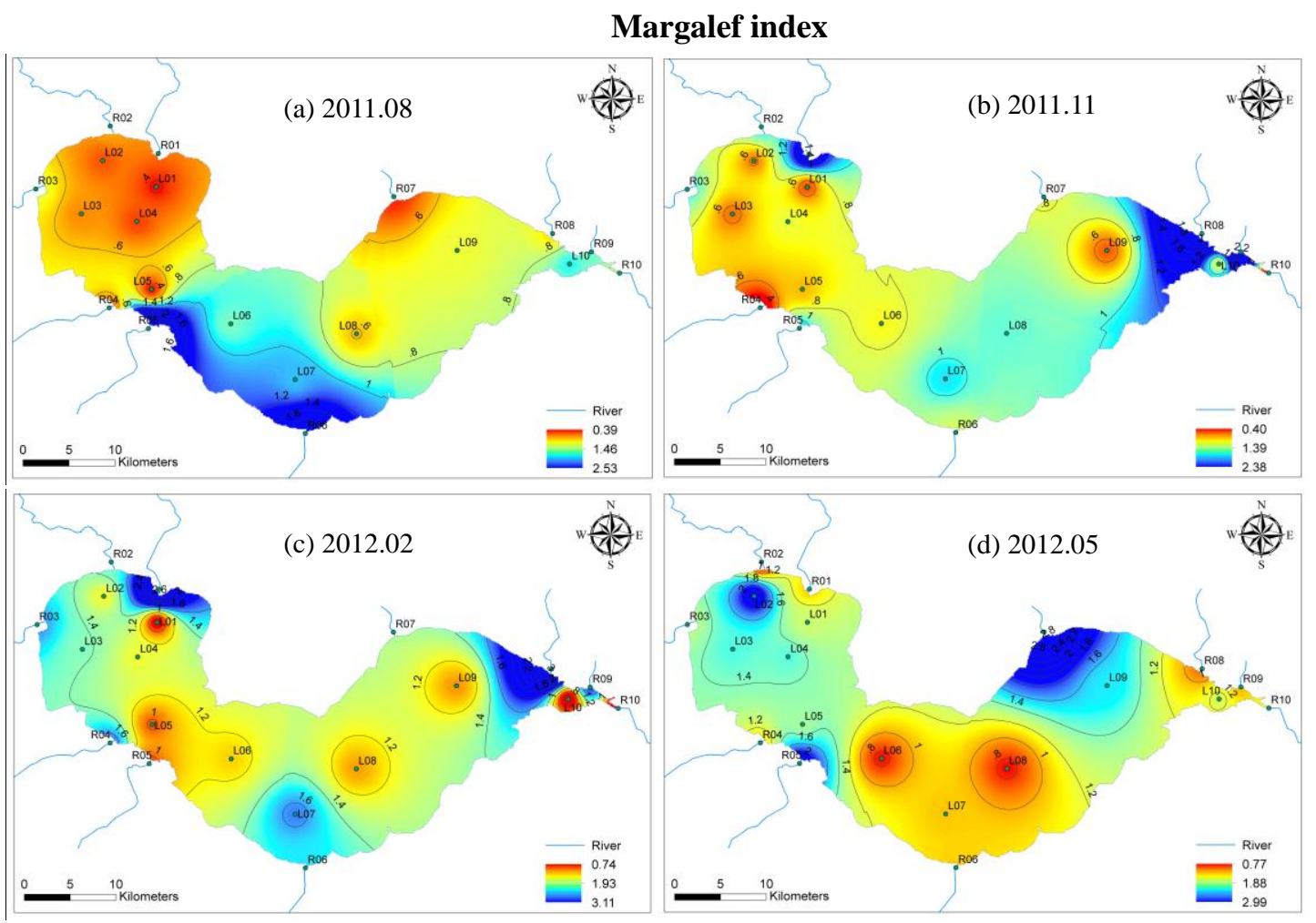

Fig. 2 The spatial distribution of phytoplankton Margalef index in Lake Chaohu during different seasons. (a) summer (August 2011); (b) autumn (November 2011); (c) winter (February 2012); (d) spring (May 2012). The interpolation map was constructed by ArcGIS software using the Inverse Distance Weighting method. 
Pielou evenness index

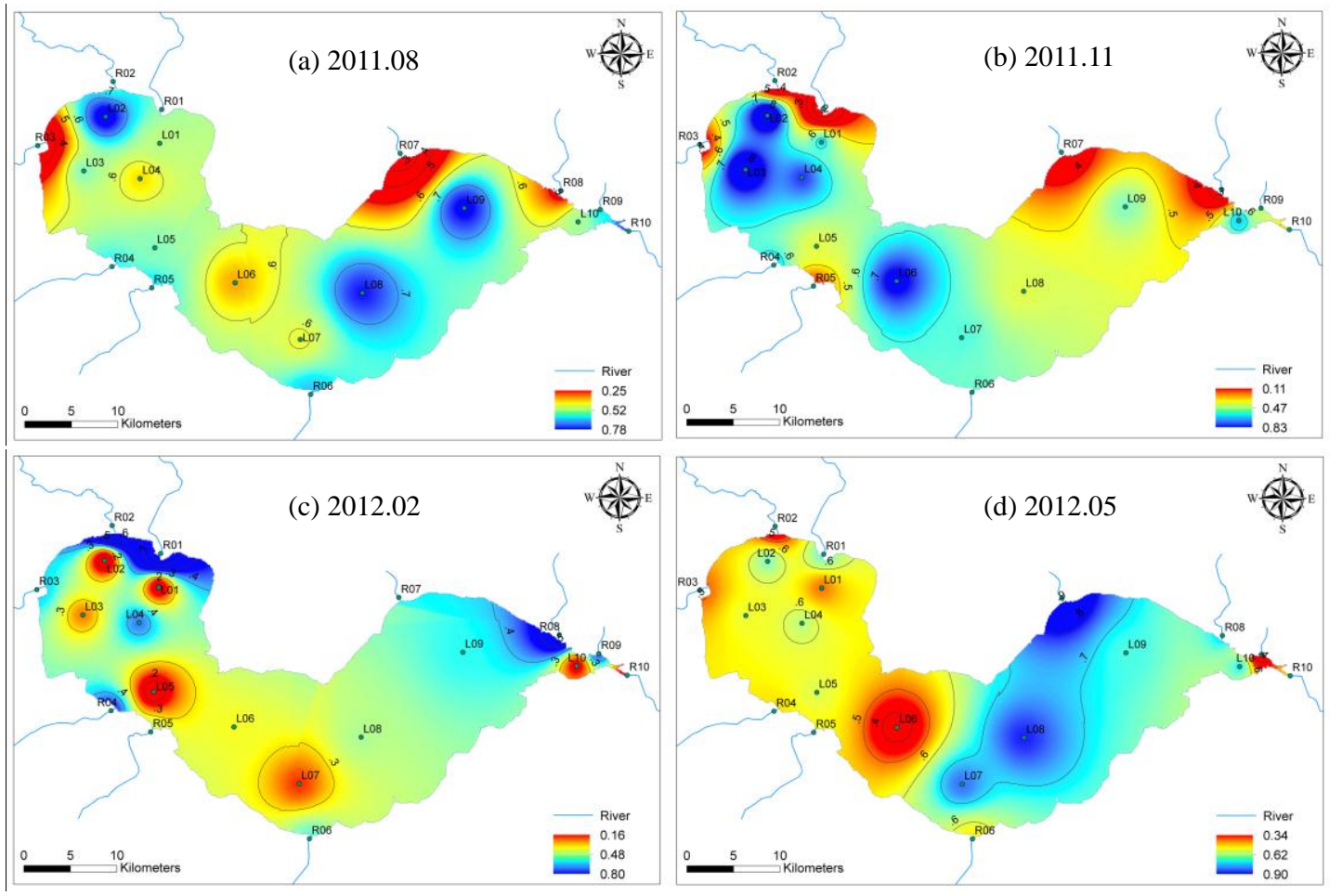

Fig. 3 The spatial distribution of phytoplankton Pielou evenness index in Lake Chaohu during different seasons. (a) summer (August 2011); (b) autumn (November 2011); (c) winter (February 2012); (d) spring (May 2012). The interpolation map was constructed by ArcGIS software using the Inverse Distance Weighting method. 
Shannon-Wiener index

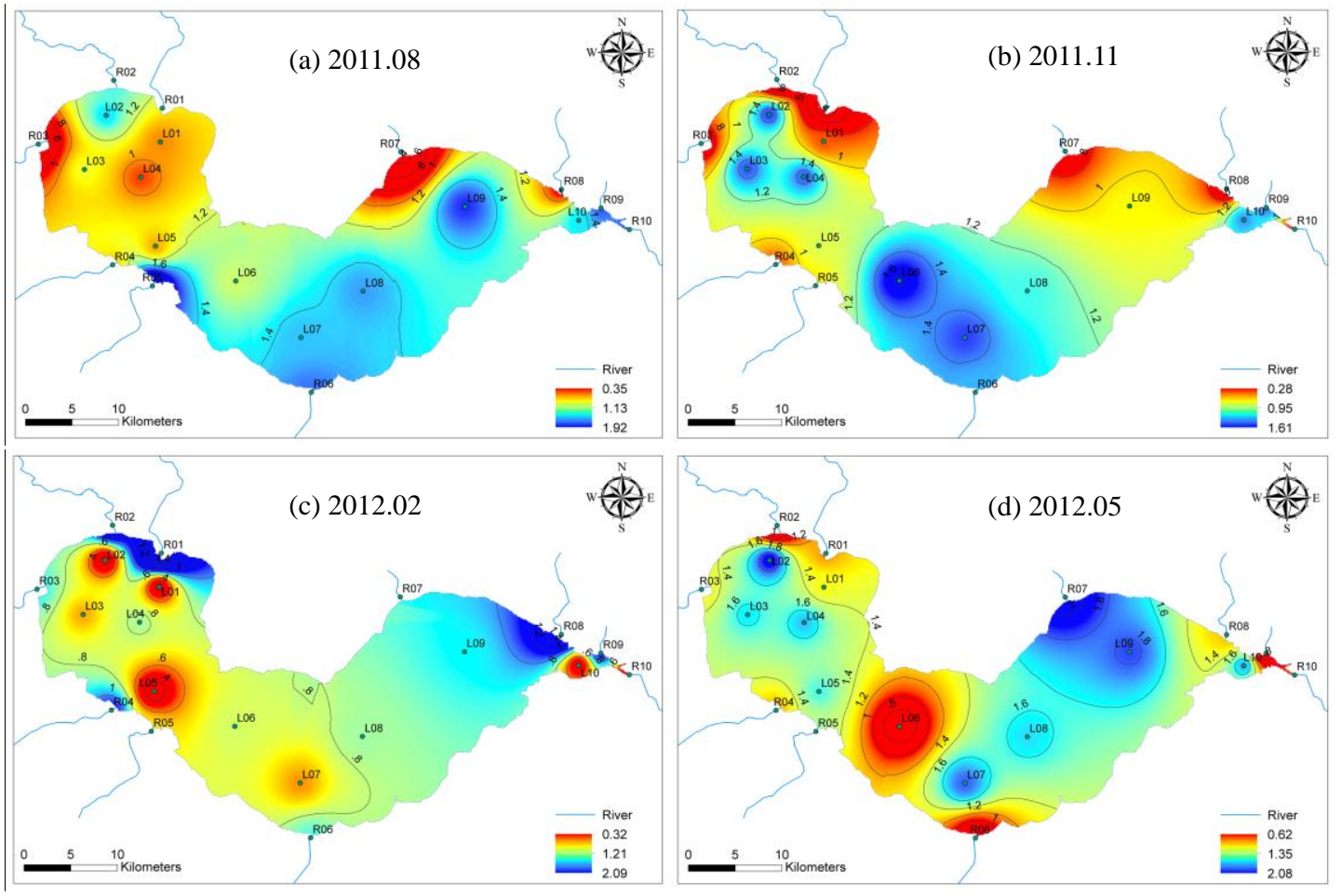

Fig. 4 The spatial distribution of phytoplankton Shannon-Wiener index in Lake Chaohu during different seasons. (a) summer (August 2011); (b) autumn (November 2011); (c) winter (February 2012); (d) spring (May 2012). The interpolation map was constructed by ArcGIS software using the Inverse Distance Weighting method. 
Simpson diversity index

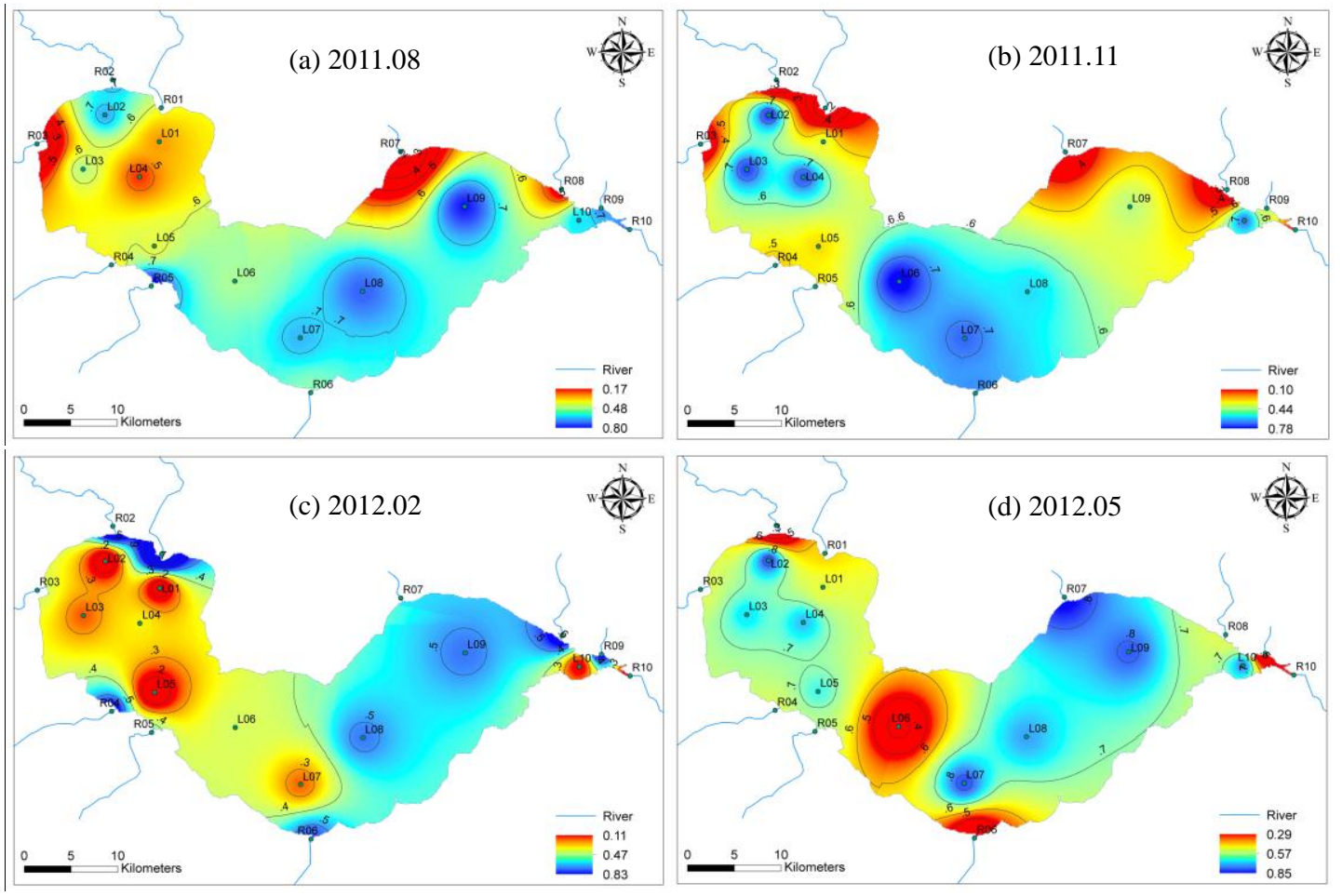

Fig. 5 The spatial distribution of phytoplankton Simpson diversity index in Lake Chaohu during different seasons. (a) summer (August 2011); (b) autumn (November 2011); (c) winter (February 2012); (d) spring (May 2012). The interpolation map was constructed by ArcGIS software using the Inverse Distance Weighting method. 


\section{Trophic state index (TSI)}
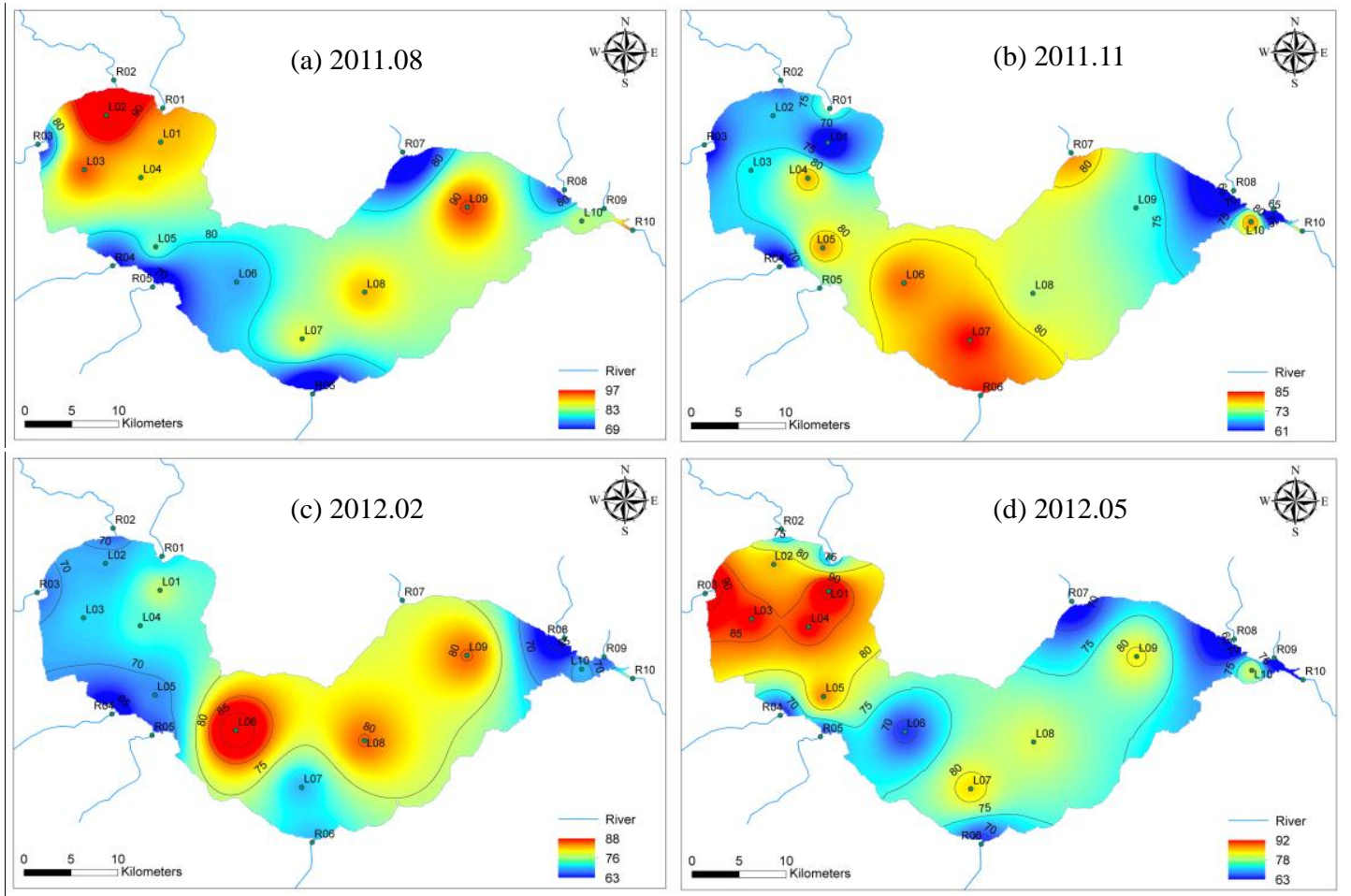

Fig. 6 The spatial distribution of TSI in Lake Chaohu during different seasons. (a) summer (August 2011); (b) autumn (November 2011); (c) winter (February 2012); (d) spring (May 2012). The interpolation map was constructed by ArcGIS software using the Inverse Distance Weighting method. 
Table 1 The seasonal and spatial variation of diversity indices and TSI in Lake Chaohu and its component rivers during the period from August 2011 to May 2012. WL: western Lake Chaohu (L01-L05); EL: eastern Lake Chaohu (L06-L10); WR: western rivers around Lake Chaohu (R01-R05); ER: eastern rivers around Lake Chaohu (R06-R10).

\begin{tabular}{|c|c|c|c|c|c|c|}
\hline & & Margalef & Peilou & Shannon-Wiener & Simpson & TSI \\
\hline \multirow[t]{4}{*}{ Aug 2011} & WL & $0.438 \pm 0.055$ & $0.653 \pm 0.078$ & $1.102 \pm 0.187$ & $0.585 \pm 0.094$ & $88.21 \pm 5.53$ \\
\hline & EL & $0.835 \pm 0.179$ & $0.658 \pm 0.095$ & $1.415 \pm 0.137$ & $0.716 \pm 0.059$ & $84.78 \pm 4.40$ \\
\hline & WR & $1.097 \pm 1.023$ & $0.569 \pm 0.197$ & $1.223 \pm 0.612$ & $0.579 \pm 0.255$ & $78.67 \pm 12.50$ \\
\hline & ER & $0.884 \pm 0.495$ & $0.564 \pm 0.203$ & $1.157 \pm 0.542$ & $0.543 \pm 0.246$ & $77.30 \pm 8.11$ \\
\hline \multirow[t]{4}{*}{ Nov 2011} & WL & $0.627 \pm 0.104$ & $0.693 \pm 0.130$ & $1.262 \pm 0.284$ & $0.649 \pm 0.121$ & $76.07 \pm 6.18$ \\
\hline & EL & $0.828 \pm 0.198$ & $0.612 \pm 0.077$ & $1.354 \pm 0.219$ & $0.684 \pm 0.077$ & $80.86 \pm 3.62$ \\
\hline & WR & $1.018 \pm 0.450$ & $0.342 \pm 0.194$ & $0.635 \pm 0.306$ & $0.308 \pm 0.187$ & $72.89 \pm 3.99$ \\
\hline & ER & $1.368 \pm 0.945$ & $0.436 \pm 0.152$ & $0.974 \pm 0.376$ & $0.438 \pm 0.192$ & $74.12 \pm 11.10$ \\
\hline \multirow[t]{4}{*}{ Feb 2012} & WL & $1.139 \pm 0.220$ & $0.242 \pm 0.108$ & $0.502 \pm 0.217$ & $0.199 \pm 0.101$ & $71.64 \pm 2.13$ \\
\hline & $\mathrm{EL}$ & $1.134 \pm 0.322$ & $0.299 \pm 0.070$ & $0.712 \pm 0.197$ & $0.376 \pm 0.142$ & $77.95 \pm 7.59$ \\
\hline & WR & $1.722 \pm 0.737$ & $0.568 \pm 0.244$ & $1.258 \pm 0.555$ & $0.591 \pm 0.198$ & $68.02 \pm 2.66$ \\
\hline & ER & $2.144 \pm 0.917$ & $0.458 \pm 0.105$ & $1.193 \pm 0.362$ & $0.573 \pm 0.040$ & $67.19 \pm 4.10$ \\
\hline \multirow[t]{4}{*}{ May 2012} & WL & $1.521 \pm 0.322$ & $0.594 \pm 0.055$ & $1.637 \pm 0.221$ & $0.740 \pm 0.062$ & $86.37 \pm 3.48$ \\
\hline & $\mathrm{EL}$ & $1.069 \pm 0.324$ & $0.652 \pm 0.171$ & $1.523 \pm 0.499$ & $0.710 \pm 0.192$ & $77.89 \pm 4.95$ \\
\hline & WR & $1.243 \pm 0.518$ & $0.537 \pm 0.104$ & $1.133 \pm 0.411$ & $0.562 \pm 0.202$ & $74.99 \pm 9.99$ \\
\hline & ER & $1.428 \pm 0.886$ & $0.614 \pm 0.208$ & $1.183 \pm 0.549$ & $0.568 \pm 0.191$ & $65.59 \pm 3.01$ \\
\hline
\end{tabular}


Table 2 The Pearson correlation coefficients of diversity indices in All samples, Lake samples (L01-L10) and River samples (R01-R10).

\begin{tabular}{|c|c|c|c|c|c|c|c|c|c|c|}
\hline \multirow[b]{2}{*}{ Samples } & & \multicolumn{3}{|c|}{ Margalef } & \multicolumn{3}{|l|}{ Peilou } & \multicolumn{3}{|c|}{ Simpson } \\
\hline & & All & Lake & River & All & Lake & River & All & Lake & River \\
\hline \multirow[t]{2}{*}{ Shannon-Wiener } & Correlation & $.366^{* *}$ & .177 & $.579^{* * *}$ & $.860^{* * *}$ & $.863^{* *}$ & $.854^{* *}$ & $.959^{* * *}$ & $.969^{* *}$ & $.950^{* *}$ \\
\hline & Sig. & .001 & .275 & .000 & .000 & .000 & .000 & .000 & .000 & .000 \\
\hline \multirow[t]{2}{*}{ Margalef } & Correlation & & & & .009 & -.297 & .234 & .161 & .001 & $.367^{*}$ \\
\hline & Sig. & & & & .937 & .062 & .163 & .163 & .995 & .025 \\
\hline \multirow[t]{2}{*}{ Peilou } & Correlation & & & & & & & $.902^{* *}$ & $.918^{* *}$ & $.884^{* *}$ \\
\hline & Sig. & & & & & & & .000 & .000 & .000 \\
\hline
\end{tabular}

* Denotes $\mathrm{p}<.05$ (two-tailed)

** Denotes $\mathrm{p}<.01$ (two-tailed) 
Table 3 The correlation coefficients found by partial correlation analysis of phytoplankton diversity indices and TSI in All samples, Lake samples (L01-L10), River samples (R01-R10), Western samples (L01-L05 \& R01-R05), Eastern samples (L06-L10 \& R06-R10) and samples in different seasons.

\begin{tabular}{|c|c|c|c|c|}
\hline Samples & & Margalef & Peilou & Shannon-Wiener \\
\hline \multirow[t]{2}{*}{ All } & Correlation with TSI & $-.726 * *$ & $-.530 * *$ & $.654 * *$ \\
\hline & Sig. & .000 & .000 & .000 \\
\hline \multirow[t]{2}{*}{ Lake } & Correlation with TSI & $-.404 *$ & $-.344^{*}$ & $.472 * *$ \\
\hline & Sig. & .012 & .034 & .003 \\
\hline \multirow[t]{2}{*}{ River } & Correlation with TSI & $-.711 * *$ & $-.511 * *$ & $.606 * *$ \\
\hline & Sig. & .000 & .002 & .000 \\
\hline \multirow[t]{2}{*}{ Western } & Correlation with TSI & $-.710 * *$ & $-.592 * *$ & $.693 * *$ \\
\hline & Sig. & .000 & .000 & .000 \\
\hline \multirow[t]{2}{*}{ Eastern } & Correlation with TSI & $-.790 * *$ & $-.512 * *$ & $.640 * *$ \\
\hline & Sig. & .000 & .001 & .000 \\
\hline \multirow[t]{2}{*}{ Summer } & Correlation with TSI & $-.768 * *$ & -.253 & $.576^{*}$ \\
\hline & Sig. & .000 & .328 & .016 \\
\hline \multirow[t]{2}{*}{ Autumn } & Correlation with TSI & $-.906 * *$ & $-.881 * *$ & $.896^{* *}$ \\
\hline & Sig. & .000 & .000 & .000 \\
\hline \multirow[t]{2}{*}{ Winter } & Correlation with TSI & $-.614^{*}$ & -.488 & $.532 *$ \\
\hline & Sig. & .011 & .055 & .034 \\
\hline \multirow[t]{2}{*}{ Spring } & Correlation with TSI & $-.499 *$ & $-.673 * *$ & $.779 * *$ \\
\hline & Sig. & .035 & .002 & .000 \\
\hline
\end{tabular}

\footnotetext{
$*$ Denotes $\mathrm{p}<.05$ (two-tailed)

** Denotes $\mathrm{p}<.01$ (two-tailed)
} 